\title{
Macroscopic Analysis of Fetus Having Arhinencephaly, Synophthalmia and Holoprosencephaly
}

Henriette Poaty ${ }^{1 *}$, David Gentien², Cecile Reyes ${ }^{2}$ and Jacques Silou ${ }^{3}$

${ }^{1}$ Laboratory of Histology, Embryology and Genetic Medical Faculty, BP 2672, University Marien Ngouabi, Brazzaville, Congo, Africa

${ }^{2}$ Plateforme Genomics, Department of Translational Research, 26 rue d'Ulm Institut Curie, 75005 Paris, France

${ }^{3}$ Mother and Child Clinic, Brazzaville, Congo, Africa

\begin{abstract}
We report here a macroscopic analysis of one fetus conserved in Bouin then in formol having an arhinencephaly, synophthalmia associated with holoprosencephaly. We aimed to relate the various etiologies of observed anomalies in conjunction with the literature review. To perform the study, a fetopathologic examination including autopsy and radiologic analysis were done. Assay of FISH and OncoScan were made. Fetopathologic examination showed severe craniofacial malformations associated with extracranial defects including persistent troncus arteriosus communis, abnormal lung lobulation, extremities deformities and single umbilical artery. FISH and OncoSan had given unsuccessful results, because nucleic acids were highly degraded. The macroscopic examination of the fetus having arhinencephaly and synophthalmia highlights asymptomatology association with holoprosencephaly sequence and visceral defects.
\end{abstract}

Keywords: Arhinencephaly; Craniofacial malformation; Holoprosencephaly; Synophthalmia

\section{Introduction}

Arhinencephaly is a complete absence of olfactive tract formation. It concerns a defect of induction of the neural plate derived from dorsal ectoderm during primary neurulation, towards 18-19th days (third week) of embryonic development (Figure 1a) [1,2]. This defect caused a failure of prosencephalon cleavage in two secondary cerebral vesicles (Figure $1 \mathrm{~b}$ and $1 \mathrm{c}$ ): the telencephalon of which derives the two (right and left) cerebral hemispheres and the diencephalon which gives thalami, hypothalamus and retina, specifically between the third and the fifth weeks of embryonic development (WED) [3,4]. The undifferentiated primitive prosencephalon vesicle remains a unilobar pocket and gives only a unique cerebral mass (holoprosencephaly). In the normal state, the prosencephalon neural crest stem cells which migrates in 4th WED, forward to the level of stomodeum orifice, leads the formation of five prominences or bud facial: single nasofrontal bud, pair of maxillary buds and pair of mandibular buds [4]. The nose results from the nasal placodes which appear on the nasofrontal bud at the 5th WED and the eyes derived from the ectodermal placodes which develop at the level of forebrain anterior (prosencephalon) [4]. The maldevelopment of prosencephalon diverticulation will in turn involve various anomalies which are at the origin of the polymalformative syndromes associating cerebral defect (as holoprosencephaly) and aberrant development of midline facial structures like the absence of the olfactory tract (arhinencephaly), partial fusion (synophthalmia) or complete (cyclopia) of ocular globes [5]. Extracranial anomalies can also be observed. Arhinencephaly is regarded as a minor clinical expression of holoprosencephaly which is a midline anomaly defined as absence or incomplete cleavage and rotation of the forebrain of various etiologies [6-8]. We report here a fetopathologic examination of a fetus having an arhinencephaly, synophthalmia associated with holoprosencephaly.

\section{Material and Methods}

\section{Fetus}

She was a decease female fetus (10F-001) at full-term (38 weeksold), delivered by cesarean section and dating back over 10 years. She derived from our faculty collection of Human Embryos without diagnosis. She was been conserved first in Bouin liquid then in formalin at 10 percentage. Placenta and family data were no available.

\section{Methods}

For a better diagnosis approach, we have done two steps of examination: radiologic analysis (X-ray without treatment) and fetal autopsy. A tentative of genetic analysis was made by fluorescent in situ hybridization (FISH) and OncoScan technique (Afffymetrix) in collaboration with the Curie Institute. The technics were performed on paraffin-embedded fetal section tissues, in which DNA for OncoScan, was extracted then amplified. The Laboratory approved the project and written informed consent was obtained

\section{Results}

\section{The fetopathologic examination}

Revealed multiple congenital abnormalities.

External macroscopic examination: Showed a cranio-facial dysmorphism including: macrocephaly with a round face, a single midline eye with two globes fused partially in median position (synophthalmia). The forehead was flat, wide and high. We also observed: ocular hypotelorism, arrhinia, microstomia, and micrognathia (Figure 2a). We have noted a large dysplastic ears, with a right nodule closed to the tragus (Figure 2b). The scalp was low established in the nape of the neck. In addition, the two hands were closed with the third

*Correspondingauthor: Henriette Poaty, Laboratory of Histology, Embryology and Genetic Medical Faculty, BP 2672, University Marien, Ngouabi, Brazzaville, Congo, Tel: (00242)06-686-57-61(Congo) or (0033) 75338 9677 (France); E-mail: henriettepoaty@gmail.com

Received November 09, 2015; Accepted February 23, 2016; Published February 25, 2016

Citation: Poaty H, Gentien D, Reyes C, Silou J (2016) Macroscopic Analysis of Fetus Having Hrhinencephaly, Synophthalmia and Holoprosencephaly. Human Genet Embryol 6: 135. doi:10.4172/2161-0436.1000135

Copyright: $\odot 2015$ Poaty $\mathrm{H}$, et al. This is an open-access article distributed under the terms of the Creative Commons Attribution License, which permits unrestricted use, distribution, and reproduction in any medium, provided the original author and source are credited. 


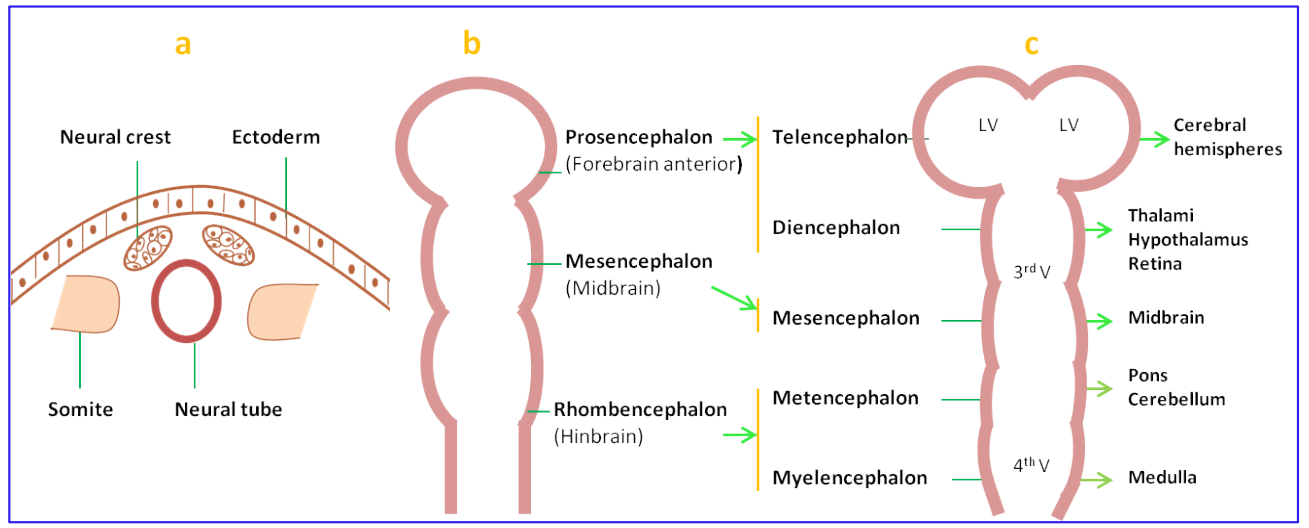

Figure 1: Cerebral development (neurulation): (a) Neural tube at 3WED, (b) Primitive cerebral vesicles at 4WED, (c) Secondary cerebral vesicles at 5 WED.

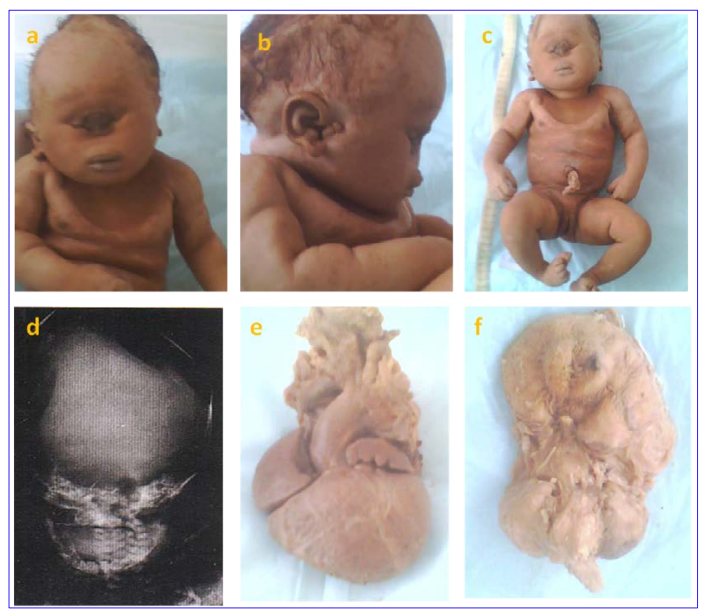

Figure 2: Fetus anomalies. (a) dysmorphic face with single eye and two globes fused medially (synophtalmia), no nose and philtrum, hypotelorism and micrognathia. (b) Profil facies: flat facies, defective relief nasal, dysmorphic large ear with abnormal presence of nodule closed in the trangus on right. Short and broad neck with excess skin. (c) Entire fetus showing extremities anomalies: closed hands and equine feet with prominent heels. (d) Radiographic imaging of cranium presenting severe facial bones anomalies associated with two partial cup orbits, absence of nasal bones and premaxillary agenesis. (e) Cardiac defect: truncus arteriosus communis with hypertrophy of right cavities (auricle and ventricle), left heart hypoplasia with castellated appearance of the auricle. (f) Encephalic anomalies: small brain (dorsal face) represented by a single cerebral mass with partial dorsal of interhemispheric sulcus, signing a semi-lobar holoprosencephaly.

right finger on the second finger, and we have noted equine feet with bilateral prominent heels (Figure 2c). The female type external genitals were normal. The others natural orifices were free and permeable. The skull X-ray without treatment permits to visualize two optic cups partially subdivided associated with an absence of olfactory tract and premaxillary agenesis (Figure $2 \mathrm{~d}$ ).

Fetal dissection showed: single umbilical artery and abnormal bilobed right lung segmentation. Heart presented severe defect with right cardiomegaly, hypoplastic left heart, persistent single arterial trunk dilated (Figure 2e) with left sided aortic arch and high and inter-ventricular communication orifice. Brain examination revealed a single ventricle and a unique cerebral mass with interhemispheric fissure agenesis on the ventral face and partial draft on the dorsal face consistent with semi-alobar HPE (Figure 2f). The commissurale structures and the corpus callosum were absent. Additionally, we noted a dilated prosencephalic vesicle. Others internal organs were examined and appeared normal. Data concerning fetus measurements (weight and viscera) are reported in Table 1 . The long impregnation of fetus in preserving liquids had increased organs weights, making the data almost unusable.
FISH and OncoScan: had given unsuccessful results. We concluded, fetus with partial cyclopia (synophthalmia) having various extracranial anomalies in addition to craniofacial malformations.

\section{Comments}

The cyclopia is a rare congenital defect, with incidence approximately to 1.05 in 100,000 births [3]. In typical form, it is accompanied with the absence of all structures present between the ocular globes. We have a single median eye in single ocular globe $[8,9]$. Therefore, synophthalmia (Figure 2a), is a variant form of cyclopia that associates a single median eye with two ocular globes partially fused in median position [5]. The nose derives from the nasofrontal bud which gives raise to the nasal placodes. The last are invaginated to form olfactory gutters at the origin of the nasal cavities and paranasal sinus [4]. Absence of prosencephalon cleavage involves a defect of nasofrontal bud development. The development of the eye uses two elements: the part of the prosencephalon which derives from the neuroectoderm and the mesodermic median structures. At three SDE, it appears the first ocular outlines are symetric: optical small cavities on the level of the prosencephaom. During the closing of the neural tube, they become at 4th WED the optical vesicles in the form of outgrowth plain with neural tube. Between 4-6 WED, the 


\begin{tabular}{|c|c|c|c|}
\hline Visceres & Weigth (g) & Index & Lenght (cm) \\
\hline Fetus weigth & 6600 & Vertex-heels (height) & 50 \\
\hline Right lung & 8.5 & Vertex-coccyx (height) & 32 \\
\hline left lung & 10.8 & $\begin{array}{c}\text { Occipito-frontal head } \\
\text { circunference }\end{array}$ & 37 \\
\hline Thymus gland & 6.2 & Thoracic circunference & 35 \\
\hline Heart & 17 & Height of ears & 3.6 \\
\hline Slpeen & 9 & Umbilical circunference & 31 \\
\hline Liver & 65.5 & & 8 \\
\hline Surrenals & 2 & & \\
\hline Right kidney & 5.6 & & \\
\hline Left kidney & 5.5 & & \\
\hline Encephal & 24 & & \\
\hline Cerebellum & 21 & & \\
\hline
\end{tabular}

Table 1: Visceral, encephal weight and biometric fetal data.

\begin{tabular}{|c|c|c|c|c|}
\hline Structures & Alobar HPE & Semi-lobar HPE & Lobar HPE & Microform HPE \\
\hline Ventral IHS & Absent & Absent & Absent & \multirow{7}{*}{$\begin{array}{l}\text { Asymptomatic } \\
\text { form without } \\
\text { neuro-anatomic } \\
\text { anomalies. } \\
\text { Submicroscopic } \\
\text { anomalies with } \\
\text { haploinsuffiency } \\
\text { of gene }\end{array}$} \\
\hline Dorsal IHS & Absent & Partial & Present & \\
\hline $\begin{array}{l}\text { Olfactiv } \\
\text { tract }\end{array}$ & Absent/single & $\begin{array}{c}\text { Absents/Present/ } \\
\text { Single }\end{array}$ & $\begin{array}{l}\text { Absent/ } \\
\text { Present }\end{array}$ & \\
\hline Optic Nerve & $\begin{array}{l}\text { Present/ } \\
\text { single }\end{array}$ & Present/Single & Present & \\
\hline Ventricles & Single & Single & Single & \\
\hline $\begin{array}{l}\text { Corpus } \\
\text { callosus }\end{array}$ & Absent & Absent & Absent & \\
\hline Thalami & Single & Single & Single & \\
\hline
\end{tabular}

Table 2: HPE classification. IHS: interhemispheric sulcus. HPE: holoprosencephaly.

optical cup takes shape by flatness and invagination of the optical vesicle. The two optical vesicles induce formation of optical placodes at the origin of optical nerves and ocular globes [4]. Synophthalmia and cyclopia that are prosencephalon diverticulation anomalies raise respectively of a partial fusion or a complete fusion of the two optical vesicles. Clinically, arhinencephaly and synophthalmia are accompanied by others severe congenital malformations, such as brain anomalies type holoprosencephaly (alobar, semi-alobar or lobar). Usually, one describes three forms of HPE $[1,10]$ summarized in the Table 2, whose diagnosis in antenatal is made with imagery (ultrasounds, scanner, IRM, tomodensitometry) [7]. Markers for neural tube development (BMP4 and SHH) in aminotic fluid and maternal serum are proposed [11]. An additional form (Table 2) was been described, in familial HPE, without clinical phenotypic expression $[12,13]$. The phenotype in the semi-lobar form associates: a single ventricle, a unique cerebral lobe with partial interhemispheric sulcus on dorsal face, an agenesis or hypoplasia of the olfactory and optical structures [1]. It is always combined with severe midline facial defect like arhinencephaly, synophtalmia observed in our case. The degree of severity of the facial abnormalities is correlated with the forebrain deficiency type [8]. That leads DeMyer [14] to write: "The face predicts the brain" in $80 \%$ of cases. However, in 10 to $20 \%$ of cases, it exists cerebral abnormalities without evident facial dysmorphism. In opposite, in inherited family etiology HPE, facial defect can be observed without cerebral anomalies [15]. Others cerebral defects described are for example: microcephaly, cebocephaly, ethmocephaly, proboscis, fused thalami, Dandy walker anomalies [15]. In our case, fetal autopsy revealed a presence of semilobar holoprosencephaly. This form is usually described as being one of the most serious. It is not compatible with life. In addition to the anomalies resulting from a defect of prosencephalon diverticulation and according to the etiology, it may been associated with extra encephalic anomalies. Indeed, the formation of the great heart vessels (aorta and pulmonary artery) also depends of neural crest cells coming from the neural tube. These stem cells are also involved in the genesis of other organs such: thymus, parathyroid, adrenal glands, lungs, kidney intestines, skelet and extremities. The defect migration of neural crest cells may explain the frequent association holoprosencephalyconotruncal malformations (Figure 2e and 2f) and the presence of other visceral anomalies. Etiologically, HPE are described as rare malformations with incidence approximately $1 / 10,000$ to $1 / 16,000$ live births $[3,6]$. They have sporadic origin or family hereditary (maternal or paternal transmission) $[16,17]$. They can be isolated (30\% of cases) or fit in clinical features of polymalformative syndromes in $25 \%$ of cases [15]. Synophthalmia, arhinencephaly and HPE involve multiple heterogenic etiologies such as chromosomal anomalies, gene mutations, and multiple teratogenic environmental factors. They are associated to chromosomal aberrations in $45 \%$ of cases [15], with in the first rank trisomy 13, provider of $70 \%$ of HPE [10]. Other chromosomal errors mentioned in the review of literature are dup (13q) or del (13q), del (18p) and trisomy $18[16,18]$. Can also be implicated: triploidy, del (2p21-2p22.2), t (6;7) (p21;q36), del (7q), t(14;18)(p11;p13), dup (16p11.2) and some diseases related to X chromosome [12]. Other etiologies have been reported like: maternal gestational diabete [19], medicamentous intoxication (retinoic acid, anticonvulsant, corticosteroids, anticancer agents, contraceptives, and cholesterol lowering drungs) and fetal alcohol exposure during the first month of pregnancy $[3,9]$. Alcohols have teratogenic effect potentiated by $\mathrm{SHH}$ and GLI2 genes haploinsuffiencies [6]. Infections during gestation are rarely pointed, it concerns especially TORCH infections: Toxoplasmosis, Others (syphilis, varicella-zoster, papovirus B19), Rubella, Cytomegalovirus and Herpes [1,20,21]. Polymalformative syndromes are pointed in 20 percentage of cases; it concerns Meckel syndrome, Smith-Lemli-Opitz syndrome (SLOS) that corresponds to 5-6\% persons having HPE [22,23], Pallister-Hall syndrome (PHS), Rubinstein-Taybi syndrome (RTS) [10]. In our report, the additional extracranial anomalies observed associated with craniofacial defect were not strongly evocative of trisomy 18 (Edwards syndrome) or trisomy 13 (Patau syndrome). To the detriment of full trisomy 13: lack of polydactyly, vertex aplasia, kidney abnormalities [24-26]. Against trisomy 18: absence of the characteristic hands, feet and no Meckel's diverticulum [26]. Polymalformative syndrome, infections or teratogenic environmental factors don't be eliminated. Concerning the gene mutations, several studies showed that holoprosencephaly is associated with mutation of some of embryonic development genes in early period. The most indexed is SHH (Sonic Hedgehog) mapped to $7 \mathrm{q} 36.3[10,13]$. Its cleavage requires the presence of cholesterol (low in the SLOS) and interactions with the transcriptional factor GLI3 located on 7p14.1 (involved in the PHS) and CBP (Creb Binding Protein) on 16p13.3, mutated in RTS. SHH specifies the midline during the development of the neural plate, inductor of the neural tube which is the precursor of the brain [6]. His mutation is responsible for aberrant development craniofacial structures) [13]. It is involved in large variable phenotypic expressivity, going of polymalformative syndrome to the isolated median cleft lip or palate [10]. Others genes mutations associated with HPE are: ZIC2 (Zinc finger protein of the cerebellum 2) flanked on $13 \mathrm{q} 3.2$ [10], it plays a part in the neurulation and the activation of SHH ; SIX3 (Sine oculis Homeobox 3) on 2p21[10], a transcriptional factor of the homeobox family, is responsible for prosencephalon and eyes anomalies; TGIF (Transforming GrowthInteracting Factor) located on 18p11.3 [16,17] belongs to the homeobox family and also involved in the cascade of SHH activation ; PATCHED on 9q22.3 is also associated with HPE [10]. But, in 10 to $20 \%$ of cases, these genes are mutated in non-syndromic diseases [15]. Concerning our fetus, the genetic analysis attempt for diagnosis confirmation was 
Citation: Poaty H, Gentien D, Reyes C, Silou J (2016) Macroscopic Analysis of Fetus Having Hrhinencephaly, Synophthalmia and Holoprosencephaly. Human Genet Embryol 6: 135. doi:10.4172/2161-0436.1000135

performed by FISH and Oncoscan. The latter method used molecular inversion probe and permits study of very old sample solid tumors (ten years or older) preserved in formalin liquid ten percentage, even in cases of altered nucleic acids. It detects chromosomal copy number aberration by studying genome-wide copy number and loss of heterozygosity in the concerned tissue. The results in our sample was negative, because of probable Bouin liquid conservation highly degraded nucleic acids. The technique seems to be in appearance no available with Bouin liquid.

\section{Conclusion}

The macroscopic examination of the fetus having arhinencephaly and synophthalmia, highlights asymptomatology association with holoprosencephaly sequence, visceral defects and extremities deformities. The no diagnosis by FISH and OncoScan which are efficient techniques also draw attention to the necessity of rigorous method in fetal conservation. The originality of our study is due to the report of rare fetus case with partial cylopia combined with severe extracephalic malformations in addition to severe craniofacial defect. The failure to do genetic testing in our case study, has called our attention on the need to develop in our laboratory, new methodologies and technics for the conservation of fetuses, in order to improve post-mortem diagnosis and enabling the development of new techniques such as OncoScan.

\section{Acknowledgments}

The work was conducted in Medical Faculty of Brazzaville. We gratefully acknowledge to Dr. Dominique Carles for critical manuscript and Dr. Denis Bedat for supervising the english text. This work was supported in part by Curie Institute. HP: designed, performed the study and wrote the paper. DG and CR: performed and analyzed OncoScan data; JS: contributing material.

\section{Conflict of Interest}

None declared.

\section{References}

1. Razavi FE, Carles D, Dauge MC, Dechelotte P, Delozoide AL, et al. (2008) Pathologie fœtale et placentaire pratique. Sauramps Médical, Montpellier.

2. David G, Haegel P (1991) Embryologie. initial development stages. fascicle 1. (4thedn) Paris : Masson. p 40-43.

3. Salama Ghassan S, Kaabney Mahmoud A, Al-Raqad Mohamed K, Al-Abdallah Ibrahim M, Sharkkouy Ayoub G, et al. (2015) Cyclopia: A rare condition with unusual presentation-a case report. Clin Med Insights Pediatr 9: 19-23.

4. Mitchell B, Sharma R (2005) Embryologie. Elsevier, Paris.

5. Howard RO (1977) Chromosomal abnormalities associated with cyclopia and synophtalmia. Trans. Am Ophthalmol Soc 75: 505-538.

6. Kietzman HW, Everson JL, Sulik KK, Lipinski RJ (2014) The Teratogenic Effects of Prenatal Ethanol Exposure are Exacerbated by Sonic Hedgehog or GLI2 Haploinsuffiency in the Mouse. PLoS ONE 9: e89448.

7. Dia Aliou A, D’Almeida F Mbodji M, Ka Mamadou M (2013) Holoprosencephaly alobar amid polymaformative syndrome: contribution of imaging in a case report. Pan Afr Med J $15: 83$

8. Carles D, Seville F, Mainguené M, Dubecq JP (1987) Cyclopia-Otocephaly association: A new case of the most severe variant of agnathiaHoloprosencephaly complex. Journ Craniofac Genet Dev Biol 7: 107-113.
9. Srinivasan KR, Joseph NA, Koteswary $P$ (2014) True cyclopia-Very rare anomaly. J Clin Diagn Res 8: AD01-2.

10. Dubourg C, Lazaro L, Blayau M, Pasquier L, Durou MR, et al. (2003) Genetic study of holoprosencephaly. Ann Biol Clin 61: 679-687.

11. Tsurubuchi T, Ichi S, Shim KW, Norkett W, Allender E, et al. (2013) Amniotic fluid and serum biomarkers from women with neural tube defect-affected pregnancies: a case study for myelomeningocele and anencephaly: clinical article. J Neurosurg Pediatr 12: 380-389.

12. Sireteanu A, Volosciuc M, Gramescu M, Gorduza E, Vulpoi C, et al. (2013) Dicentric chromosome $14 ; 18$ plus two additional CNVs in a girl with microform holoprosencephaly and Turner stigmata. Balkan J Med Genet 16: 67-72.

13. Odent S, Atti-Bitach T, Blayau M, Mathieu M, Aug J, et al. (1999) Expression of the Sonic hedgehog $(\mathrm{SHH})$ gene during early human development and phenotypic expression of new mutations causing holoprosencephaly. Hum Mol Genet 8: 1683-1689.

14. DeMyer W, Zeman W, Palmer CG (1964) The face predicts the brain: Diagnostic significance of median facial anomalies for holoprosencephaly (arhinencephaly). Pediatrics 34: 256-263.

15. Savastano Pagani C, El-jaick KB, Costa-Lima MA, Abath CM, Bianca S et al. (2014) Molecular analysis of Holoprosencephaly in South America. Genetic and Molecular Biology 37: 250-262.

16. Chen CP, Huang JP, Chen YY, Chem SR, Wu PS, et al. (2013) Chromosome $18 p$ deletion syndrome presenting holoprosencephaly and premaxillary agenesis : prenatal diagnosis and aCGH characterization using uncultured amniocytes. Gene 527: 636-641.

17. Portnoï MF, Gruchy N, Marlin S, Finkel L, Denoyelle F, et al. (2007) Midline defects in deletion 18p syndrome: clinical and molecular characterization of three patients. Clin Dysmorphol 16: 247-252.

18. Müenke M, Emanuel BS, Zackai EH (1988) Holoprosencephaly: association with interstitial deletion of $2 p$ and review of the cytogenetic literature. Am J Med Genet 30: 929-938.

19. Capobianco G, Cherchi PL, Ambrosini G, Cosmi E, Andrisani A, Dessole S (2007) Alobar holoprosencephaly, mobile proboscis and trisomy 13 in a fetus with maternal gestational diabetes mellitus : a $2 \mathrm{D}$ ultrasound diagnosis and review of the literature. Arch Gynecol Obstet 275: 385-387.

20. Sanae A, Mounia $Y(2014)$ Alobar holoprosencephaly secondary to CMV infection. Pan Afr Med J 17: 8.

21. Stegmann BJ, Carey JC (2002) Torch infections. Toxoplasmosis, Other (syphilis, varicella-zoster, papovirus B19), Rubella, Cytomegalovirus (CMV) and Herpes infections. Curr Womens Health Rep 2: 253-258.

22. Weaver DD, Solomon BD, Akim-Samson K, Kelley RI, Müenke M (2010) Cyclopia (synophtalmia) in Smith-Lemli-Opitz Syndrome : First reported case and consideration of mechanism. Am J Med Genet 154C: 142-145.

23. Verloes A, Ayme S, Gambarelli D, Gonzales M, Le Merrer M, et al. (1991) Holoprosencephaly-polydactyly (pseudotrisomy 13) syndrome : a syndrome with features of hydrolethalus and Smith-Lemli-Opitz syndromes. A collaborative multicentric study. J Med Genet 28: 297-303.

24. Wu J, Springett A, Morris JK (2013) Survival of trisomy 18 (Edwards syndrome) and trisomy 13 (Patau syndrome) in England and Wales: 2004-2011. Am J Med Genet A 161A: 2512-2518.

25. Poaty H, Peko JF, Maugey Laulom B, Taine L, Carles D (2010) Fetal trisomy 13 about 5 cases. Revue Africaine de Pathologie 9: 31-39.

26. Deschamps F, Faure JM (1998) Congenital malformations of the fetus. Sauramps Medical, Momtpellier. 